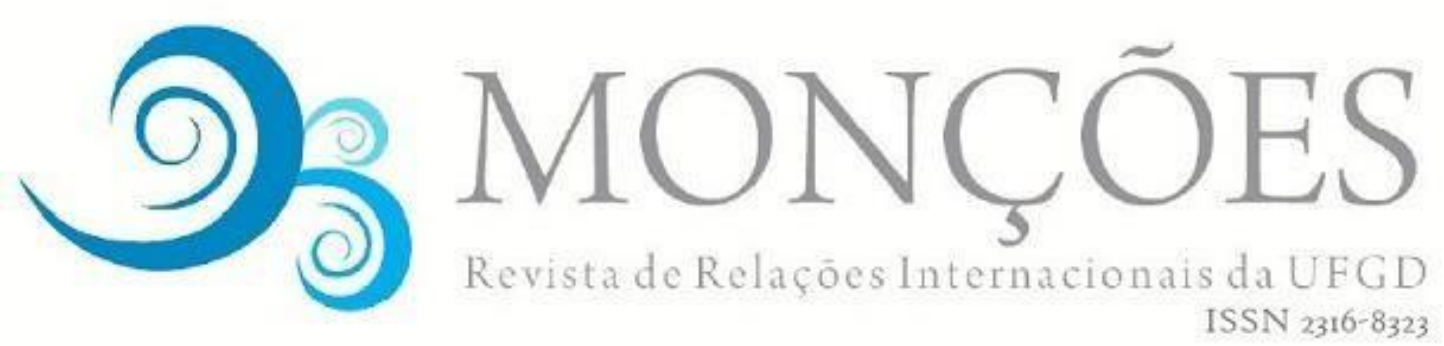

\title{
POR UMA VIRADA PÓS-SECULAR: O FEMINISMO ISLÂMICO E OS DESAFIOS AOS FEMINISMOS (SECULARES) EM RELAÇÕES INTERNACIONAIS'
}

\author{
ANA PAULA MAIELO SILVA \\ Professora do Departamento de Relações Internacionais da UEPB \\ Doutora em Ciência Política pela UNICAMP. \\ MONIQUE DE MEDEIROS LINHARES \\ Graduanda em Relações Internacionais pela UEPB
}

RACHEL EMANUELLE LIMA LIRA FARIAS DE MELO

Graduanda em Relações Internacionais pela UEPB

\begin{abstract}
RESUMO: O presente artigo analisa as principais reivindicações do feminismo islâmico e os desafios que este movimento encontra ante os estudos feministas em Relações Internacionais (RI), mesmo num contexto supostamente mais plural e aberto a novas epistemologias e ontologias. Identifica-se, por um lado, a existência de um grande hiato entre os estudos feministas e a religião, a não ser, naturalmente, pela crítica de grande parte destes estudos de que a religião é inerentemente patriarcal e, por extensão, opressora. Por outro lado, argumenta-se, que esta lacuna é oriunda da metanarrativa secular que respalda a produção de conhecimento da ciência moderna e, por conseguinte, os estudos de gênero. Finalmente, defende-se que a metanarrativa secular reifica o papel da ciência como a única forma legítima de enunciação e, que por se constituir em oposição à religião, acaba criando binários tais como secular/espiritual, razão/obscurantismo, ciência/religião, liberdade/opressão. Destarte, estes binários têm sido responsáveis por silenciar e excluir as narrativas e as experiências de mulheres muçulmanas em seus países e diásporas muçulmanas.
\end{abstract}

PALAVRAS-CHAVE: Feminismo, Feminismo Islâmico, Relações Internacionais.

\section{FOR A POST-SECULAR TURN: ISLAMIC FEMINISM AND THE CHALLENGES TO (SECULAR) FEMINISM IN INTERNATIONAL RELATIONS}

\begin{abstract}
This article analyzes the main claims of Islamic feminism and the challenges that this movement faces in the feminist studies in International Relations (IR), even in a supposedly more plural context opened to new epistemologies and ontologies. On the one hand, there is a great gap between feminist studies and religion, except, evidently, by the critique of most of these studies that religion is inherently patriarchal and, by extension, oppressive. On the other hand, it is argued that this gap stems from the secular metanarrative that supports the production of knowledge of modern science and, therefore, gender studies. Finally, it is argued that the secular metanarrative reifies the role of science as the only legitimate form of enunciation and, by constituting itself in opposition to religion, ends up creating binaries such as secular/spiritual, reason/obscurantism, science/religion, freedom/oppression. Thus, these binaries have been responsible for silencing and excluding the narratives and experiences of Muslim women in their countries and Muslim diasporas.
\end{abstract}

KEYWORDS: Feminism, Islamic Feminism, International Relations. 


\section{Introdução}

A inserção das questões de gênero em Relações Internacionais (RI) tem tido um impacto inegável que pode ser percebido pelo crescente número de pesquisas e publicações de feministas na área. Entretanto, o reconhecimento da importância dos estudos de gênero, tanto sobre seu papel na produção de conhecimento como sobre suas implicações nas dinâmicas da política internacional, é muito recente se comparado às outras áreas das ciências sociais.

Os estudos feministas tiveram impacto na disciplina das $\mathrm{Rl}$ apenas no final da década de 1980 e início de 1990. Watson (2008) afirma que as questões de gênero foram efetivamente legitimadas como questões de RI a partir da publicação de uma edição especial sobre gênero do periódico Millennium: Journal of International Studies no ano de 1988, em que Fred Halliday (1988) ressaltou que, diferentemente de outras áreas das ciências sociais, a disciplina de RI havia negligenciado o papel do gênero na constituição do sistema internacional.

A incorporação do feminismo naquele momento está associada à abertura para uma maior pluralidade teórica que presenciava a disciplina. Essa abertura teórica fez parte do denominado "quarto debate"1 entre positivistas e pós-positivistas, que foi marcado por contendas de cunho epistemológico, ontológico e metodológico sobre as fundações da disciplina de RI.

Como argumentam Tickner e Sjoberg (2013), embora os pós-positivistas tenham demorado a considerar as questões de gênero em seus estudos, seus posicionamentos de cunho epistemológico, ontológico e metodológico abriram espaço para que uma gama ampla de problemáticas ganhasse relevância nos estudos da política mundial, incluindo, naturalmente, as reivindicações feministas.

Entretanto, nem todas as abordagens feministas em RI são pós-positivistas. Algumas feministas, como as denominadas liberais, estão envolvidas com o estudo empírico das mulheres nas posições de liderança na política internacional. Diferentemente da pergunta "quem conhece?", que move os pós-positivistas, estas

\footnotetext{
${ }^{1}$ Yosef Lapid (1989) identifica o debate entre positivistas e pós-positivistas como "terceiro debate" contrariamente à Weaver (1996) e Kurki e Wight (2010) que se referem ao "terceiro debate" como sendo o debate interparadigmático (entre o realismo, o liberalismo e a herança marxista) e, por extensão, o debate entre positivistas e pós-positivistas como "quarto debate" (KURKI; WIGHT, 2010, p.20; WAEVER, 1996, p.150-151). Este artigo adota a perspectiva de Weaver e Kurki e Wight.
} 
feministas pautam-se pela questão "onde estão as mulheres?" e acreditam que o aumento na participação das mulheres nos processos políticos existentes por si só já contribuiria para a superação de sua marginalização política e econômica (STERLING-FOLKER, 2006, p.244).

Entre as feministas pós-positivistas ou pós-liberais ${ }^{2}$ há um denominador comum na dimensão epistemológica e na dimensão ontológica. Quanto à primeira dimensão, elas ressaltam a relação entre produção de conhecimento e poder, afirmando que grande parte do conhecimento tem sido produzido por homens e é sobre homens (TICKNER; SJOBERG, 2013, p.197). No que se refere à dimensão ontológica, as feministas pós-liberais desvinculam gênero da relação comumente estabelecida com o sexo biológico dos indivíduos, associando-o, pois, a um conjunto de características que são social e culturalmente construídas e enfatizando a forma como o sistema internacional é formado por hierarquias de gêneros, em que as características masculinas são mais valorizadas do que as femininas.

Apesar do reconhecimento do avanço nos debates acadêmicos em RI e da existência de uma ampla gama de ontologias e epistemologias nos estudos feministas, há ainda algumas lacunas e questões a serem respondidas pelos estudiosos de gênero. Uma das problemáticas mais importantes, que constitui um grande desafio com o qual as feministas precisam lidar, é o feminismo islâmico.

Como um movimento recente, de caráter político-religioso, o feminismo islâmico tem gerado debates sobre o papel da mulher no mundo muçulmano, ao questionar a visão feminista secular que responsabiliza o Islã pela opressão da mulher nessa sociedade. Nesta acepção, ele problematiza muitos pressupostos das diferentes vertentes feministas e de suas lutas, mas substancialmente os seus pressupostos seculares (BALDI, 2010, p.65-9).

$O$ feminismo islâmico reivindica ser um conjunto de atitudes plurais que buscam, dentro de um referencial centrado no Islã, verificar potencialidades emancipatórias no discurso e na prática, em relação às mulheres. Assim, Badran (2009) argumenta que as mulheres muçulmanas têm como pleito a revisão das

\footnotetext{
${ }^{2}$ Termo que J. Ann Tickner (2011) utiliza para caracterizar as feministas que compartilham alguns dos pressupostos pós-positivistas.
} 
tendências masculinizadas dentro do islamismo, na busca por desenvolver "uma consciência feminista dentro dos movimentos islamistas".

Dado que a religião é um traço fundamental na formação da identidade destas mulheres, elas não vêem o Islã como um empecilho para uma sociedade mais igualitária. Neste sentido, o movimento islâmico argumenta que as práticas patriarcais não são essenciais ao Islã, mas são interpretações social e historicamente contingentes. E, por extensão, muitas feministas islâmicas acreditam que o engajamento com questões teológicas e com os textos sagrados as coloca em contato com as fontes que foram utilizadas para construir e legitimar as interpretações patriarcais o que, consequentemente, pode habilitá-las a reinterpretar estes textos à luz de uma maior igualdade de gênero. (AHMAD, 2015, p.4-8).

Embora não se possa falar em consenso entre as diferentes vertentes do feminismo ocidental, deve-se reconhecer que a literatura sobre gênero atrela, ao mesmo tempo, as questões de autonomia e emancipação feminina a premissas seculares e universais e, conforme afirma Salem (2013), exime-se de reflexões que abordem as relações específicas sobre mulher, religião e autonomia.

Esse silêncio certamente traduz uma negatividade com relação à religião. $\mathrm{E}$ a não possibilidade de dialogar com algo que é parte essencial da identidade feminina de várias mulheres, implica a exclusão das narrativas e das experiências das mesmas. Isto reproduz e legitima a ideia de que a igualdade de gênero e a emancipação feminina só podem ter lugar fora da religião. Por conseguinte, o feminismo islâmico tende a ser visto como um oximoro pelos estudos feministas.

Conforme demonstra Lima (2014), o feminismo islâmico é um resultado do encontro entre o feminismo secular e os movimentos de mulheres pela reislamização e, embora recente, o movimento pós-anos 2000, além de já estar presente na maior parte das sociedades muçulmanas, já podia ser presenciado nas diásporas muçulmanas, principalmente, nas dos EUA e nas da Europa (LIMA, 2014, p.676). Este fato torna ainda mais sintomático este hiato existente entre os estudos feministas e a religião nas ciências sociais em geral, mas, principalmente, nas RI.

Tendo em vista a importância destas questões, bem como a urgência de tirálas do "anonimato" em RI, o presente artigo pretende, por um lado, analisar as reivindicações e as experiências do feminismo islâmico e, por outro, os desafios que este movimento encontra comumente na literatura de gênero particularmente em RI. 
Por que, a despeito da subversão epistemológica e ontológica com a tradição positivista, as feministas pós-positivistas não estabeleceram um diálogo com o feminismo islâmico? Argumenta-se que as origens desse impasse devem ser compreendidas à luz dos binários ciência/religião, secular/espiritual, razão/obscurantismo, liberdade/opressão. Ainda, advoga-se que estes binários são oriundos da metanarrativa secular da ciência moderna e das relações de poder nela inscritas. Portanto, um reencontro com a religião e o reconhecimento de sua legitimidade seria, para a ciência, uma subversão da sua referencialidade racional (e narcisista) como única interpretação legítima do mundo? Será possível promover uma reconciliação entre ciência e religião?

Ao responder estas questões, este artigo pretende ser uma contribuição original no campo da epistemologia na área de Teoria das RI. Ressalte-se que até o presente momento, não há pesquisas na área de RI no Brasil que se debruçam sobre o feminismo islâmico e tampouco sobre o debate secularismo versus pós-secularismo, que ultrapassa o já não tão novo debate positivismo versus pós-positivismo em Rl ${ }^{3}$.

Para tanto, a primeira seção deste artigo será dedicada a examinar os debates entre algumas das vertentes feministas categorizadas na literatura de RI, com vistas a analisar os seus postulados para, então, compreender o alcance e o limite dos mesmos no que diz respeito às reivindicações do feminismo islâmico. Na seção subsequente, as reflexões serão pautadas pelos aspectos mais importantes do feminismo islâmico e de suas reivindicações, buscando apontar como este movimento tem encontrado empecilhos ante os estudos feministas seculares.

\section{Os feminismos e a inserção do debate de gênero em Relações Internacionais}

Conforme argumenta Smith (1996), a disciplina de RI tem sido dominada pelo positivismo, que apresenta uma visão unificada da ciência, bem como adota metodologias das ciências naturais para explicar o mundo social. Assim, o autor

\footnotetext{
${ }^{3}$ É importante esclarecer que embora reconheça-se a existência e a importância do debate sobre religião nas $\mathrm{RI}$, este debate tem natureza ontológica. Em outras palavras, neste debate a religião é colocada como um objeto de estudo das RI e não como um lugar originário de produção de conhecimento legítimo (SHILLIAM, 2011, p.23). E o escopo deste trabalho é justamente questionar, dentro dos estudos de gênero, esta forma de interlocução com as questões religiosas, advogando por um debate no plano da própria produção de conhecimento. O debate secularismo versus póssecularismo que aqui se propõe para se refletir sobre Teoria de RI é, portanto, epistemológico.
} 
ressalta que a disciplina tende a aceitar, implicitamente, um conjunto simples e, fundamentalmente, incontestável de pressupostos positivistas que inviabilizam o debate sobre o que é o mundo e de que forma podemos explicá-lo. Isso, notadamente, deve-se ao fato de que os questionamentos que emergem dessas abordagens marginalizam importantes questões epistemológicas.

Grande parte da literatura disponível em RI, até pelo menos o final da década de 1980, reproduz a história do desenvolvimento da disciplina a partir dos "grandes debates"4, conferindo um status de pluralismo ao campo de estudo da política internacional. Smith (2010) afirma, no entanto, que essa noção de pluralismo intelectual, segundo a qual sempre existiram diferentes abordagens em condições equivalentes de concorrência, é falsa. Em diferentes publicações ${ }^{5}$, o mesmo autor demonstrou que o ensino e a produção de conhecimento em RI foram dominados pelas bases da epistemologia positivista e, em particular, pelos pressupostos do realismo em suas diferentes vertentes.

As abordagens críticas, também denominadas pós-empiricistas ou póspositivistas (CAMPBELL, 2012), ganharam maior visibilidade no campo de estudo das RI na década de 1980 e 1990 e, ao questionar a validade do positivismo, negam a existência de uma linguagem universal e à correspondente teoria da verdade, opondose, assim, ao pensamento fundacional para a produção de conhecimento. Sob o mesmo viés crítico, Cynthia Weber (2010) aponta para a "função-mito" que as teorias clássicas de $\mathrm{Rl}$ desempenharam no estudo das relações internacionais. Ao estabelecerem as supostas verdades absolutas e inquestionáveis sobre 0 funcionamento da política internacional, as premissas das abordagens clássicas exercem a função dos mitos, ou seja, transformam uma visão de mundo que é particular, cultural e ideológica em algo aparentemente universal, natural e puramente empírico (WEBER, 2010, p.6-7).

Para Weber (2010), a disciplina de RI deve ser estudada como um local de prática cultural. Ao mesmo tempo, as tentativas de naturalização do que é cultural por parte das teorias clássicas de RI precisam ser analisadas à luz das complexas redes

\footnotetext{
${ }^{4}$ Para maiores detalhes sobre os debates, consultar: WEAVER, $O$. The rise and fall of the interparadigm debate. In: SMITH, S.; BOOTH, K.; ZALEWSKI, M. (eds.) International Theory: positivism \& beyond. New York: Cambridge University Press, 1996.

${ }^{5}$ Ver, por exemplo: Smith, S. (1996); Smith, S. (2000); Smith, S. (2002); Smith, S. (2010)
} 
de poder, que são justamente as responsáveis pela função mito destas abordagens. Assim, argumenta-se, aqui, que uma vez que não se pode escapar dessa função mito, é imprescindível devolver à produção de conhecimento o seu caráter político e compreender os seus reflexos sobre as diferentes formas de manifestação do poder na própria prática das relações internacionais.

Numa aparente ironia, Cynthia Enloe (1996) se diz impressionada com o fato de que grande parte das análises de política internacional seguem subestimando as diferentes formas de poder que são necessárias para formar e sustentar qualquer conjunto de relações entre os estados. Essa asserção, consoante a autora, soa estranho já que os teóricos clássicos das RI focaram boa parte de seus estudos nas formas de alcance e manutenção do poder (ENLOE, 1996, p.186). Contudo, o problema, imperceptível para muitos estudiosos, é que o foco das abordagens tradicionais sobre o considerado "centro" (a política das grandes potências) omite, necessariamente, as múltiplas e intrincadas hierarquias de poder que criam e mantêm este "centro", bem como outros "centros", e, por extensão, as "margens" 6 .

Aqueles que constituem as margens, ou seja, que se encontram na base das pirâmides de poder ${ }^{7}$, não obstante possuam características e reivindicações distintas, compartilham a falta de poder público e o fato de serem, via de regra, o objeto do poder de outras pessoas e/ou grupos. E, embora estas "margens" tenham pouca ou nenhuma influência sobre o curso de alguns eventos na esfera internacional, a omissão desta problemática implica numa imagem simplista, enviesada e, sobremaneira, limitada de todo o sistema político. Primeiramente, porque esta omissão assume que as "margens" são um fenômeno natural sem qualquer relação com a criação e o posicionamento dos "centros". E, por conseguinte, essa presunção leva à incompreensão dos fenômenos e movimentos que emergem das "margens" como formas de subversão das relações desiguais de poder (ENLOE, 1996).

Estas problemáticas levantadas pelas vertentes críticas em RI foram essenciais para evidenciar como e porque uma ampla gama de reivindicações de natureza epistemológica e ontológica foi marginalizada e silenciada pelas teorias clássicas.

\footnotetext{
${ }^{6}$ Ao utilizar-se "centros" e "margens" no plural, intenta-se dizer que dentro de cada periferia ou centro há outros micro centros e micro periferias.

${ }^{7}$ Cynthia Enloe se utiliza da expressão micro pirâmides justamente para ressaltar o fato de que o poder se manifesta de forma múltipla e em várias camadas da sociedade, criando pirâmides (relações desiguais) de poder dentro de outras pirâmides.
} 
Neste contexto, encontram-se as abordagens feministas que surgiram com vistas a contestar o foco ontológico e epistemológico convencional da disciplina. Argumentava-se que para que as questões feministas fossem inseridas em Rl, era necessário haver uma reestruturação na disciplina, de maneira a alterar a forma como as relações internacionais eram entendidas e estudadas (WEBER, 2010).

Conforme explicita True (2005), os estudos feministas em RI começaram a se expandir no início dos anos de 1990. Rejeitando a suposta neutralidade de gênero da política internacional, estes estudos foram responsáveis por introduzir gênero como uma categoria empírica e como um instrumento analítico relevante para o entendimento das relações de poder em âmbito global, bem como para apresentar uma posição normativa com vistas a propor a construção de ordens mundiais alternativas (TRUE, 2005).

Embora não seja o foco deste artigo analisar em profundidade os debates em torno da ressonância dos estudos de gênero na disciplina RI, é importante mencionar brevemente a recepção que as reivindicações e pesquisas feministas tiveram ante as teorias clássicas. No famoso artigo "You just don't understand" de J. A. Tickner (1997), a autora argumenta que uma das principais razões para o que ela denomina "troubled engagements between Feminists and IR Theorists" encontra-se nas diferenças ontológicas e epistemológicas entre os dois grupos. Assim, Tickner (1997) faz um forte apelo para que as pesquisas feministas ganhem legitimidade e sejam amplamente reconhecidas pelas teorias clássicas de RI, como condição primária para um melhor entendimento entre as diferentes abordagens e propostas de pesquisa.

Contudo, a barreira aparentemente intransponível entre as feministas e o mainstream manifesta-se quando Robert O. Keohane, no artigo Beyond Dichotomy, em resposta à Tickner, afirma que: 'We will only 'understand' each other if IR scholars are open to the important questions that feminist theories raise, and if feminists are willing to formulate their hypotheses in ways that are testable - and falsifiable - with evidence". (KEOHANE, 1998, p.197) Ou seja, Keohane acaba corroborando a "hipótese" que Tickner (1997) formula em seu artigo para explicar os desentendimentos entre eles, a saber: feministas e teóricos clássicos repousam suas pesquisas em ontologias e epistemologias distintas. E, por conseguinte, isto também reforça a ideia de que suas desavenças são insuperáveis. 
A despeito disto, os estudos feministas indiscutivelmente causaram um impacto na disciplina de RI, na medida em que inseriram uma nova visão acerca do papel das mulheres na política internacional ao atribuir a elas uma função relevante como ator histórico e político. Apesar destas conquistas, é preciso reconhecer que as teorias feministas se pautam por uma grande variedade de perspectivas de campos de estudos distintos. Isto resulta numa crescente diversidade de produção acadêmica feminista, o que gera diferentes percepções sobre como a teoria e a prática das RI são afetadas pelas questões de gênero.

Assim, faz-se necessário pontuar que nem toda teoria feminista é póspositivista. As feministas liberais, por exemplo, reivindicam a igualdade de direitos entre mulheres e homens ressaltando a necessidade de o estado promover políticas e reformas sociais que garantam oportunidades iguais para mulheres e homens. Desta forma, as interlocutoras dessa vertente se preocupam em apontar os papéis e trabalhos desempenhados por mulheres na esfera pública, assumindo que a marginalização econômica e política das mulheres poderia ser superada pelo seu envolvimento nos processos políticos vigentes (STERLING-FOLKER, 2006, p.244).

Como Steans (1998) reconhece, as feministas liberais tiveram uma contribuição importante ao disseminar seus argumentos a favor da inclusão das mulheres na política e, por conseguinte, em termos práticos, conseguiram trazer as questões de gênero para a agenda da política internacional. Entretanto, elas são alvo de sérias críticas elaboradas pelas feministas pós-liberais, as quais questionam as fundações normativas da teoria feminista liberal e a sua ênfase no individualismo.

Uma das críticas repousa na negligência liberal da análise das estruturas sociais que favorecem a desigualdade de gênero. Sob o ponto de vista teórico, argumenta-se que as liberais são omissas com relação às distorções e aos preconceitos de gênero que acabaram sendo aceitos e normalizados na disciplina de RI. Ainda, ao aceitar as distinções entre público/privado, político/não-político, as feministas liberais, segundo Whitworth (1997), aceitam a visão liberal de que as mulheres têm sido tradicionalmente excluídas das relações internacionais porque guerra, diplomacia e alta política não são questões de interesse das mulheres.

Outro contraponto importante, feito particularmente pelas feministas negras e pós-coloniais, é que o feminismo liberal reflete apenas os valores de mulheres brancas de classe média (WATSON, 2008). Do mesmo modo, elas examinam como a 
linguagem liberal da liberdade e dos direitos das mulheres acabou por encobrir interesses econômicos ocidentais em contextos de intervenção como, por exemplo, no Oriente Médio (RUBY, 2002).

Em comum, portanto, estas pesquisadoras possuem a crítica ao feminismo liberal e a preocupação em relação à construção de gênero. De uma forma geral, elas desafiam as teorias clássicas de $\mathrm{Rl}$ e o feminismo liberal no que se refere a sua suposta natureza neutra em relação ao gênero. Peterson e Runyan (1999) ressaltam que muitas feministas em RI concordam com o fato de que existe uma tendência no pensamento científico ocidental de criar hierarquias e/ou oposições que são tratadas como naturais ou dadas. E, por conseguinte, apesar das grandes diferenças culturais nos papéis de gênero, as características relacionais do masculino e do feminino são sempre hierárquicas, sendo as características masculinas via de regra mais valorizadas e privilegiadas (STERLING-FOLKER, 2006).

É necessário, ainda, notar que mesmo estando alicerçadas em posicionamentos epistemológicos não positivistas, as perspectivas feministas pósliberais trazem uma rica diversidade de pressupostos e reivindicações e, conquanto utilizem "lentes de gênero" como um instrumento analítico, ao se pautarem por perspectivas teóricas distintas, elas trazem diferentes respostas para as suas problemáticas.

As denominadas feministas radicais sustentam que as relações de subordinação e dominação entre mulheres e homens constituem uma das formas mais relevantes de opressão (WATSON, 2008). Ao contrário das feministas liberais, as radicais acreditam que a organização patriarcal do mundo afeta tanto 0 funcionamento do mundo como a produção de conhecimento sobre o mesmo e, por isto, a simples inclusão de categorias de análise que contemplem mulheres não é suficiente porque as próprias normas e padrões de pesquisa das ciências sociais são fruto do pensamento masculino.

Neste aspecto, as feministas radicais acabam por superar algumas das questões de natureza epistemológica das feministas liberais, conforme aponta Whitworth (1997), já que elas afirmam que as feministas liberais repousam suas pesquisas na mesma noção de verdade absoluta das teorias clássicas das RI. Outra crítica relevante feita às liberais diz respeito à associação que as mesmas fazem entre o público e o político. Ao rejeitarem esta identificação, as feministas radicais reforçam 
a ideia de que "o pessoal é o político". Uma implicação importante dessa asserção é o abandono da ideia de que RI deve contemplar apenas as questões da "alta política", relativas à segurança e à guerra (WHITWORTH, 1997, p.18).

Entretanto, uma das lacunas que podem ser identificadas nesta abordagem é que, embora não seja um consenso entre todas as feministas radicais ${ }^{8}$, algumas delas argumentam que as mulheres são mais pacíficas do que os homens e que é uma inevitabilidade biológica o fato de os homens serem mais agressivos, hierárquicos e territoriais do que as mulheres (WHITWORTH, 1997, p.17). Este posicionamento, ao atribuir características supostamente essenciais ao feminino e ao masculino, torna-se um dos principais pontos de contenda entre esta variante e outras perspectivas que defendem o gênero como uma construção social (KIMMEL, 2004).

Outra limitação que merece destaque é o fato de que apenas pensar sob uma ótica feminista não contribui para alterar efetivamente as bases materiais que promovem e sustentam as relações desiguais entre homens e mulheres. Além disto, substituir a versão masculina pela feminina reproduz os mesmos binários criados por uma visão essencialista dos sexos e, ao mesmo tempo, ignora as diferentes reivindicações de mulheres de outras gerações, classes, raças, culturas e religiões.

Com vistas a apresentar um quadro analítico alternativo, as feministas pósestruturalistas e pós-coloniais buscam, primariamente, desconstruir o próprio significado de mulher e argumentam que todo e qualquer discurso, incluindo os discursos de mulheres, são parciais e existem apenas dentro de um conjunto específico de relações de gênero.

Tickner e Sjorberg (2013) argumentam que gênero é entendido por estas feministas como uma construção social que emerge de práticas que conectam as ideias e os argumentos em todos os níveis da política e da sociedade, incluindo o internacional. Elas se preocupam em analisar o significado trazido pelas ideias e como este é codificado através da linguagem. A principal questão postulada por essas perspectivas envolve a relação entre conhecimento e poder, sobre o que pode ser falado e quem pode falar. Estas feministas argumentam que os homens são

\footnotetext{
${ }^{8}$ É importante ressaltar que nenhuma vertente feminista deve ser entendida como uma teoria monolítica e universal. Entre as suas interlocutoras, há sempre uma série de contendas. Contudo, o que se busca aqui é analisar o denominador comum que existe entre as autoras classificadas as diferentes categorias disponíveis na literatura de gênero em RI, a fim de compreender as divergências entre as mesmas.
} 
justamente aqueles que têm sido considerados como os detentores de conhecimento e, assim, aquilo que é reconhecido como conhecimento reflete, em grande medida, as experiências de homens na esfera pública (HOOPER, 2001). Essa asserção é reforçada também por Sylvester (1996) e Spivak (2010), na medida em que estas autoras buscam "dar voz" às pessoas que foram marginalizadas, no caso, as mulheres e, com isso, romper os pressupostos positivistas de que as experiências não importam e de que existe neutralidade na produção acadêmica.

O feminismo pós-colonial, conquanto tenha raízes nos pressupostos pósestruturalistas, enfatiza, particularmente, que as relações de dominação e subordinação estabelecidas sob o imperialismo permaneceram intactas a despeito da independência das ex-colônias. Estas relações se fazem presentes justamente no conhecimento ocidental. As feministas pós-coloniais advogam que as feministas liberais e radicais têm construído conhecimento sobre as mulheres não ocidentais como se as problemáticas das mulheres fossem universais ou formassem uma categoria homogênea (MOHANTY, 1984; CHOWDHRY; NAIR, 2002). Destarte, os estudos calcados nesta tipologia apresentam um posicionamento crítico frente às reivindicações universalistas das mulheres ocidentais e, por extensão, buscam evidenciar que a subordinação de gênero reflete a interseção de gênero, raça e cultura e está entrelaçada à política, à economia e a outras relações de dominação/subordinação (TICKNER; SJOBERG, 2013, p.202).

Por sua vez, a teoria crítica feminista busca desenvolver um entendimento da política internacional calcado na análise da interação recíproca de três forças, a saber: as condições materiais, as ideias e as instituições. Segundo estas pesquisadoras, as ideias são importantes na medida em que legitimam as instituições. Por isto, elas buscam evidenciar as ideias associadas às mulheres e aos homens que informam as práticas de certos atores e de determinadas instituições, bem como ressaltam as condições materiais e as forças sociais que contribuem para a reprodução destas práticas. E, considerando que as ideias são o produto de agentes, as feministas críticas afirmam que há sempre a possibilidade de mudança. Portanto, suas pesquisas têm um caráter fortemente comprometido com a emancipação das relações desiguais de poder de gênero.

De fato, as feministas críticas compartilham com as pós-estruturalistas o entendimento de que gênero é uma condição de desigualdade socialmente 
construída. Porém, os estudos feministas críticos defendem que para se compreender como se dão estas construções e a atribuição de comportamentos às mulheres e aos homens, o foco da análise deve ser as condições materiais e hábitos, práticas e discursos de atores e instituições nacionais e internacionais (CHIN, 1998). Por isto, os significados devem ser buscados a partir dos papéis desempenhados pelos atores em circunstâncias particulares e, assim, a construção social pode ser, como defende Whitworth (1997), descoberta sem escorregar para a regressão indefinida e a paralisia política que, segundo ela, caracteriza o pós-modernismo.

Locher e Prügl (2001), interlocutoras do feminismo construtivista, apresentam uma contraposição importante aos pressupostos das feministas críticas, particularmente concernente à sua concepção de poder. As autoras afirmam que as feministas críticas concebem a construção de gênero como parte um sistema mais amplo de subordinação (capitalismo, patriarcado ou a intersecção de ambos). Para os estudos que se utilizam dessa premissa, a construção de gênero emerge de uma ideologia revelada em crenças, ideias e instituições que estabilizam o sistema. $O$ poder está, portanto, localizado nestas ideologias e, dessa forma, é externo às identidades. Assim, os Estados, as firmas e as organizações internacionais desempenham um papel seminal na construção de gênero ao disseminar uma ideologia hegemônica que facilita certas formas de capitalismo.

O grande problema, como apontam Locher e Prügl (2001), é que as feministas que seguem estes parâmetros negligenciam o fato de que a formação de identidades é um processo excludente e, com isto, acabam tratando gênero como um status social que se intersecta com outros status, como etnia, classe, etc., com vistas a realizar várias formas de super ou subordinação contextualmente específicas. Por este motivo, as feministas construtivistas se dizem compartilhar das concepções de poder pós-estruturalistas já que estas não descrevem o poder como ideologia, mas o vê localizado no próprio processo de formação das identidades.

Nesta acepção, a subordinação das mulheres é vista pelas feministas construtivistas, assim como pelas pós-estruturalistas e pós-coloniais, como estando emaranhada nos discursos modernos, que são estruturados por binários tais como: mulher/homem; ocidente/oriente; civilizado/não civilizado; doméstico/externo; eu/outro; etc. De modo que o primeiro termo dos binários permanece sempre como a fonte de agência e legitimidade e, consequentemente, o segundo termo se torna o 
ponto de referência negativa, em oposição ao qual o primeiro termo se constitui. No processo de formação das identidades, o "eu" emerge através da negação ou exclusão do "outro". O "eu" é codificado em termos de raça, etnia, gênero, etc.

Gênero é, assim, segundo Locher e Prügl (2001), um código poderoso porque ele é co-constituído com o sexo, seu correlato supostamente "natural". Nesse processo, as dicotomias ou binários e as ordens simbólicas estabelecem uma relação estrutural entre gênero e sexo e, consequentemente, unem cultura e biologia e fazem emergir uma realidade de gênero aparentemente abrangente e natural. Como um código para poder, gênero e sexo contribuem para sustentar as identidades modernas (LOCHER; PRÜGL, 2001, p.117). Diferentemente das feministas críticas, portanto, as feministas construtivistas, pós-estruturalistas e pós-colonialistas afirmam que as construções de gênero não são ideologias impostas por atores ou instituições particulares, mas são aspectos fundacionais do sujeito moderno, uma variável imprescindível à formação das identidades.

Os trabalhos que respaldam suas análises no construtivismo social concentram-se nos elementos ideacionais da política internacional mais do que nos materiais. E, apesar das diferenças entre as autoras, que refletem as distintas versões do construtivismo social, todas elas advogam pela incorporação da esfera social como base para a compreensão das relações internacionais. Consequentemente, as feministas construtivistas veem as estruturas e os agentes como co-consitutivos e ressaltam a forma como as ideias sobre gênero moldam e são moldadas pela política internacional.

Conforme analisado, a inserção das problemáticas e reivindicações das diferentes vertentes feministas foi fundamental para questionar a supremacia do escopo conservador das teorias clássicas em RI e para subverter sua epistemologia e ontologia calcadas na tradição positivista. Entretanto, após refletir sobre os principais aspectos dessas abordagens urge debruçar-se sobre o tema central deste artigo, o feminismo islâmico. A problemática que aqui se quer levantar é que após a análise de uma vasta literatura e do reconhecimento dos importantes avanços que as teorias feministas trouxeram para a produção de conhecimento em RI, constatou-se a existência de um grande hiato entre estes estudos e a religião. Assim, o feminismo islâmico depara-se com sérios desafios para legitimar suas experiências e 
reivindicações ante à produção de conhecimento sobre gênero nas ciências sociais, em geral, bem como nas RI.

Diante deste contexto, várias questões são suscitadas: as reivindicações do movimento feminista islâmico estariam indo de encontro ao trabalho intelectual e ativista das feministas que defendem a autonomia e a emancipação das mulheres? Ora, se feminismo e religião são incompatíveis, então feminismo islâmico seria um oximoro? Ou, o não encontro com a religião por parte das feministas não estaria silenciando e excluindo as experiências de muitas mulheres? Esta exclusão não seria paradoxal para os próprios pressupostos de algumas das feministas que evocam "dar voz aos silenciados", legitimando sua fala? Não estariam estas feministas reificando os binários secular/espiritual; razão/obscurantismo liberdade/opressão tão caros à tradição positivista a qual elas contestam? Será possível promover um reencontro entre ciência e religião? Estas questões serão analisadas na seção subsequente.

\section{O feminismo islâmico e o desafio ao feminismo secular como a única forma de contribuir para um mundo pós-patriarcal}

\section{O feminismo islâmico e suas reivindicações}

É de caráter indispensável romper com a visão ocidental de que as mulheres muçulmanas são vítimas de sua própria cultura ou religião. Por isso, muitas intelectuais, bem como ativistas do movimento de mulheres em comunidades muçulmanas $^{9}$, buscam romper com essa perspectiva ao pontuar a articulação do discurso e da prática feminista a partir ou dentro de um paradigma islâmico. Neste contexto, encontra-se o feminismo islâmico, que é caracterizado como um movimento

\footnotetext{
${ }^{9}$ Uma das pioneiras do feminismo islâmico é a poetisa persa Tahirih de Qazvin que, através do seu papel dentro do movimento Babí, inspirou várias mulheres a assumirem a liderança na esfera religiosa e na esfera pública. Outro nome importante é o da ativista indiana Sharifa Khanam, que ganhou notabilidade ao criar um jamaat feminista, como resposta ao sistema jamaat tradicional que oprime a mulher através de uma visão patriarcalista da sharia. Já a ativista paquistanesa Sabin Malik contribuiu para o movimento feminista islâmico ao iluminar a questão do desencorajamento do uso do véu (hijab) pelas muçulmanas, após o 11 de setembro. Malik busca o combate contra os extremismos que acabam por manchar a imagem do Islã no mundo ocidental. Também é importante mencionar o nome das intelectuais Fatima Mernissi, Asma Barlas e Amina Wadud que seguem pelo mesmo viés questionador do discurso patriarcal presente nas práticas religiosas e propõem, assim, a releitura do Alcorão sob uma perspectiva feminista (MARQUES, 2010).
} 
recente, de caráter político-religioso, e que tem ampliado os debates acerca do papel da mulher no mundo muçulmano, de modo a questionar a visão feminista secular que responsabiliza o Islã pela opressão da mulher nessa sociedade (LIMA, 2014).

Como reitera Lima (2014, p.675), o feminismo islâmico é "uma expressão da intersecção da modernidade com o Islã". Padro (2008) reforça esse argumento ao explicitar que o surgimento dessa vertente do feminismo é marcado pela ojeriza ao feminismo ocidental, que propõe a superação da religião, e do abandono do Islã como o caminho possível para se alcançar a liberdade da mulher no mundo muçulmano.

A emergência histórica do feminismo islâmico se dá, consoante Franco (2006), no contexto da relação dialética entre o islamismo e suas diretrizes do retorno às tradições ortodoxas, as quais reservavam à mulher um lugar privado e secundário na sociedade. Destarte, o movimento apresentou-se como uma rejeição ao retorno a estas tradições, reivindicando uma revisão às leis do Islã. Em termos históricos, o início da década de 1890 pode ser identificado como uma das raízes do feminismo islâmico já que foi naquele período, na Turquia e no Egito, que emerge algo em torno do que Lima (2014) denomina "consciência feminista", a partir de publicações com inspiração nos modos de vida seculares franceses e estadunidenses. Porém, foi apenas em 1920 que o movimento se organizou, particularmente no Egito, sob a liderança de Huda Sha'rawi, que fundou, em 1923, a União das Feministas Egípcias.

Entretanto, naquele momento, as ideologias e reivindicações eram ainda bem distintas das problemáticas atualmente pleiteadas pelas feministas Islâmicas. Ahmed (1992), Badran (2009) e Lima (2014) ressaltam que as diferentes gerações de militantes e intelectuais no Egito, embora tenham plantado as sementes para o feminismo islâmico, foram caracterizadas por significativas alterações ideológicas e instabilidades, bem como pela rejeição do conceito feminista secular.

O surgimento do feminismo islâmico no Egito, argumenta Lima (2014) pode ser representado por três gerações: a primeira geração (1936-1980), conservadora e tradicionalista, ressaltava o papel primordial da mulher na formação dos filhos observadores do Islã com vistas a criar uma sociedade verdadeiramente islâmica. A segunda (1980-1990), não obstante reivindicasse o direito das mulheres à educação, trabalho e espaços públicos, posicionava-se contra o feminismo por considerá-lo ocidental. Por fim, a terceira geração (pós-1990), denominada "islamista progressista", 
possuía mais afinidades com o feminismo e propunha o fim das dicotomias sociais, tais como feminino/masculino, público/privado, religioso/secular.

$\mathrm{Na}$ Turquia, o surgimento do movimento feminista islâmico pode ser remontado aos desdobramentos de quatro períodos, quais sejam: (i) período Tanzimat (18391923), ligado ao momento da reforma modernizadora otomana; (ii) intervenções nacionais e ocidentais da República Kemalista (1923-1960); (iii) o "feminismo de Estado" (1960-1990) e (iv) o feminismo secular kamalista e sua reação denominado feminismo secular crítico ao kemalismo (1960-1990).

Assim, as raízes do feminismo islâmico encontram-se na reforma modernizadora otomana, entre as décadas de 1839 e 1923 (KARAM, 1998). É neste contexto que a posição da mulher passou a ganhar espaço nos debates públicos e intelectuais. Segundo Lima (2014), nesse período observou-se a realização de algumas reformas nos direitos das mulheres. Porém, essas "reformas" eram, em grande parte, fruto de um pensamento nacionalista e, por isto, na prática, acabaram não rompendo com os padrões patriarcais impostos. Isso, por sua vez, fora alvo de grandes críticas por parte das mulheres islamitas e, sob a pressão das mesmas, algumas mudanças passaram a ser implementadas na defesa pelos direitos das mulheres turcas.

Subsequente a esse período, a Turquia viveu sob o regime de Kemal Ataturk, o qual implantou o que foi denominado de "feminismo de Estado", que se tratava de uma política nacionalista e ocidentalista de reforma dos direitos das mulheres, nos quais obtiveram bastante avanço. Porém, não se admitia a ação de grupos feministas organizados que não fossem do governo, os quais eram fortemente reprimidos. Essa última concepção também se encontrava contida no que fora denominado como "feminismo secular kemalista" que, não por acaso, sofreu inúmeras críticas por parte de um grupo feminista que viera a ser denominado de "feminismo secular crítico ao kemalismo".

O "feminismo secular crítico ao kemalismo" buscava uma maior inclusão das mulheres ao movimento, visto que, como supramencionado, havia ainda certa restrição. Contudo, esse feminismo apresentava uma concepção de que o Islã era um dos responsáveis pela opressão feminina. Este entendimento somente será revertido a partir dos anos de 1990, com a presença de um debate que, finalmente, permitiu a 
formação de uma nova consciência de gênero a partir do feminismo e da religião (KARAM, 1998; LIMA, 2014).

Tendo surgido historicamente no Egito e na Turquia, Margot Badran (2005) destaca que o feminismo islâmico não se configura como um movimento monolítico. Ele emergiu a partir de diferentes manifestações e em lugares distintos. Além disto, o feminismo islâmico pode ser considerado um fenômeno global e amplo, pois não se trata de um movimento originado em um único país, de modo que transcende o Oriente e o Ocidente, principalmente tendo em vista que o movimento passou a ser contemplado ao redor do mundo por mulheres dentro do seu próprio país de origem, bem como em países com minorias muçulmanas.

Todavia, como um denominador comum, o feminismo Islâmico advoga que o patriarcado vigente em países islâmicos está relacionado às tendências masculinizadas que ocorrem dentro do islamismo. Em outras palavras, Franco (2016, p.87) expõe que o movimento busca questionar os "fundamentos da religião a partir de uma perspectiva interna". À luz de uma perspectiva crítica das mulheres no âmbito do feminismo islâmico, advoga-se que as desigualdades nos papéis que são desempenhados por homens e mulheres na família e na sociedade não estão contidas no escrito sagrado - o Alcorão -, mas, em contrapartida, na "dinâmica social que é apreendida culturalmente" (FRANCO, 2016, p.87).

Desta forma, argumenta-se neste estudo que o feminismo islâmico foi um divisor de águas entre as vertentes feministas devido ao seu caráter questionador da visão secular de mundo que aponta a religião, a exemplo do Islã, como uma instituição necessariamente opressora da mulher. Nesse contexto, conforme Ahmad (2015), o feminismo Islâmico busca evidenciar que a religião não é inerentemente opressora e, para isto, se pauta no pressuposto central de que a estrutura patriarcal vigente em países islâmicos está relacionada às interpretações masculinizadas feitas do Alcorão e não ao escrito em si. Assim, essa abordagem feminista advoga que a tradição e as práticas culturais tiveram uma grande influência nessas interpretações e propõe, com isto, uma releitura das leis sagradas à luz da perspectiva feminina (BELLOTTI, 2007).

Ainda, as feministas islâmicas reiteram a necessidade de desprovincializar o feminismo, trazendo para si a tarefa de verificar potencialidades emancipatórias no discurso e na prática das mulheres islâmicas, como um meio para ampliar o papel da mulher no mundo muçulmano, além de certificar que as reivindicações respeitem os 
anseios particulares de cada localidade. Na busca por desenvolver "a feminist consciousness within the Islamist movements" (BADRAN, 2009, p.216), as mulheres que anteriormente eram vistas como "invisíveis", passam a ser consideradas membros ativos da sociedade (AHMAD, 2015). Porém, apesar da inegável ressonância que estas reivindicações têm ganhado junto às comunidades muçulmanas, a autora elucida que a sua recepção pela "elite privilegiada masculina", principalmente no plano privado, tem encontrado forte resistência, mesmo que na esfera pública as mulheres tenham atingido certa emancipação.

Ao afirmarem que não é a religião, per si, a responsável pela opressão, mas, sim o conjunto de normas, crenças e práticas patriarcais que estão arraigadas na sociedade muçulmana, as feministas islâmicas reivindicam que a reinterpretção do texto sagrado, e não a negação do mesmo, constitui uma forma de escapar das práticas opressoras e, a partir daí, mudar as tradições patriarcais que permeiam a cultura muçulmana com vistas a atingir uma sociedade mais igualitária e justa. Para Badran (2002), de fato o Islã tem sido um meio para salvaguardar o patriarcado, porém a autora também entende que isto foi resultado de processos culturais e históricos. Entretanto, a visão hegemônica que persiste é a do chamado "Islã patriarcal", o que contribui para deslegitimar e inviabilizar a luta pela igualdade de gênero no âmbito do feminismo islâmico.

Ahmad (2015) recorda que na época do profeta Maomé, as mulheres tinham liberdade para participar ativamente da sociedade, em suas esferas sociais e religiosas. Entretanto, após a morte do profeta, observou-se a marginalização da mulher, a sua exclusão da esfera pública, assim como, a sua subjugação no espaço privado. É possível recorrer, portanto, a diferentes contextos históricos da tradição islâmica na história da sociedade muçulmana, para compreender como muitas práticas foram socialmente construídas (AHMAD, 2015; MACK, 2003).

Com isso, atribui-se à religião um caráter que é "acidental" ${ }^{10}$, que diz respeito a essa construção histórico-social das práticas culturais e que, em detrimento disso, seriam passíveis de mudança. Não obstante, entende-se também que o Islã possui um caráter "essencial", que representa o cerne da religião, não sendo passível de

\footnotetext{
${ }^{10}$ Esta expressão é utilizada com base no exemplo que Ahmad (2015) cita da tese defendida pela pensadora islâmica iraniana Abdul Karim Soroush, que busca fazer uma distinção entre o que são elementos "acidentais" do Islã e o que é essencial à ele.
} 
mudança, e é para esse princípio que as feministas islâmicas pretendem retornar, através da reinterpretação do texto sagrado (AHMAD, 2015). É precisamente a partir destas duas características atribuídas ao Islã que se pode proceder a um exercício de diálogo com as abordagens feministas analisadas na seção anterior do artigo.

O pós-secularismo e os desafios aos feminismos em RI

Quais são os caminhos para se refletir sobre possíveis conexões entre o Islã e o feminismo? Por um lado, a literatura sobre feminismo islâmico advoga pela subversão da visão hegemônica acadêmica ocidental acerca desta religião, apresentando-a como outra forma para se avançar na igualdade de gênero nas comunidades muçulmanas. Por outro lado, Salem (2013) afirma que, apesar da pluralidade das abordagens feministas seculares, é notório o silêncio entre essas teóricas no que se refere à relação entre feminismo e religião. Esse silêncio é reflexo da concepção, por grande parte dos estudiosos de gênero, sobre a religião como essencialmente patriarcal e opressora. Tal afirmativa legitima a ideia de que as mulheres religiosas não são providas de autonomia e agência e, por esta razão, não possuem meios para a emancipação.

Este entendimento feminista secular suscita inúmeras questões. Como sustenta Ridzuan (2011), ao reduzir os ideais do feminismo islâmico aos entendimentos de emancipação, autonomia e agência, próprios do feminismo secular, primeiramente, reforça-se a predominância da narrativa do referencial teórico e analítico hegemônico, ou seja, o ocidental e secular. Como consequência, naturalizase essa narrativa celebrando-a como a única forma de se pensar o feminismo e as possibilidades de alcançar igualdade de gênero. Isto leva ao silenciamento da narrativa do feminismo islâmico, à ausência de auto-reflexão por parte das feministas seculares e à reprodução de noções hegemônicas nos trabalhos de estudiosos acerca de mulheres inseridas em contextos religiosos.

Para as feministas liberais, a agência significa o livre exercício para se comportar e fazer escolhas e é somente a partir dessa liberdade que se pode atingir a emancipação. Esta ontologia liberal da agência enquadra o debate sobre a religião em termos de escolhas feitas por mulheres versus "escolhas" foçadas pela religião às mulheres (SALEM, 2013). Ou seja, as liberais reivindicam direitos iguais para 
mulheres e homens e é com base nestes direitos que se julga que as religiões são essencialmente patriarcais. Salem (2013) argumenta que a análise da autonomia segue o mesmo critério, qual seja, o exercício da escolha também é definido em termos da contenda entre o individualismo e a tentativa de subjugação do mesmo por poderes externos. Neste sentido, portanto, mais uma vez, o Islã é visto como o poder externo que reforça a relação de dependência das mulheres e extirpa qualquer capacidade de agência ou autonomia já que elas se submetem aos dogmas religiosos, em contraposição à sociedade secular, supostamente livre para fazer as suas escolhas.

Defende-se que retratar o feminismo a partir deste parâmetro da "liberdade para escolher", reifica noções de agência como central para o feminismo e, conforme aponta Salem (2014) suscita questões tais como: o que fazer, então, quando mulheres "escolhem" ser parte de estruturas que veem os homens como superiores e, assim, reproduzem formas de desigualdade de gênero. Esse é um paradoxo que esta noção feminista tem grande dificuldade para responder. Em segundo lugar, este discurso assume que existem escolhas de fato e que estas podem ser feitas fora de relações de poder (SALEM, 2013). Ora, argumenta-se que escolhas nunca são livres, dado que elas em tempo algum estão fora de estruturas de poder ou sistemas hegemônicos.

As feministas críticas conseguem superar estas questões de ordem epistemológica porque reconhecem que escolhas não são livres. Mas, apesar disto e do fato de elas admitem as diferenças culturais em relação ao gênero, estas estudiosas compreendem a opressão feminina e a incapacidade de agência e o patriarcado como parte de um sistema amplo de subordinação, quão seja o capitalismo. A religião é, pois, uma das instituições sociais que, imersa na ideologia do patriarcado, oprime as mulheres. Uma vez que o poder é visto por esta vertente como localizado em ideologias e, por isto, externo às identidades dos indivíduos, as mulheres, cuja religião é parte integral de suas identidades (e se recusam a abrir mão dela), encontram pouca ou nenhuma abertura para contemplar as suas reivindicações de que é possível se pensar em emancipação por meio da religião.

Talvez, seja possível encontrar uma brecha nos estudos feministas calcados nas vertentes construtivista, pós-estruturalista e pós-colonial. Estas feministas, como já visto, concebem gênero e as identidades como uma construção social que emergem de práticas que conectam as ideias e os argumentos em todos os níveis da 
política e da sociedade. Ainda, estas abordagens reconhecem que as mulheres são constituídas por uma vastidão de experiências e subjetividades e, a partir disto, elas ampliam a noção de opressão, tendo em vista as diferentes camadas e combinações em que ela pode ocorrer: classe, raça, gênero, incapacidades físicas, etc. Neste aspecto, elas prontamente corroboram a premissa do feminismo islâmico sobre o caráter "acidental" do Islã, ou seja, o patriarcado.

Todavia, algumas ressalvas devem ser feitas. Primeiramente, as autoras feministas pós-estruturalistas e pós-colonialistas são antifundacionalistas e advogam que todo e qualquer discurso existe apenas num conjunto específico de relações de gênero, negando qualquer essência ou naturalidade de entendimentos, interpretações e relações particulares. Estas asserções constituem um empecilho para o argumento das feministas islâmicas sobre aquilo que é "essência" do Islã e que pode ser identificado por meio de experiências transcendentais e com o encontro com o divino.

Mesmo ao tentar reconceitualizar a noção de agência como originalmente apresentada pelas feministas liberais (e até mesmo construtivistas), pósestruturalistas e pós-coloniais não conseguem reconciliar agência com a religião. Segundo Salem (2014), Judith Butler, uma das representantes mais emblemáticas nos estudos de gênero, bem como outras autoras que bebem nas mesmas tradições teóricas, entendem que ao utilizarem a religião para contestar normas sociais, as mulheres religiosas estão demonstrando uma capacidade de ação. Ou seja, a agência e a autonomia podem ser identificadas na presença de desafios ao poder. Entretanto, Mack (2003), Mahmood (2004) e Salem (2013) argumentam que embora estas autoras não admitam, esta reconceitualização permanece dentro dos parâmetros do conceito liberal já que ainda se pautam na agência como um conceito fundamental para se entender e se praticar o feminismo.

As feministas construtivistas, mesmo não sendo antifundacionalistas, entendem a agência como uma condição social. Ou seja, os indivíduos agem no mundo apenas como seres sociais. E é apenas a partir da relação de co-constituição entre agentes e estruturas que se pode conceber os códigos de poder responsáveis pela formação das identidades destes agentes. Assim, a agência reflete "escolhas" que não são livres, mas que estão entrelaçadas às regras e padrões de comportamento que são construídas, compartilhadas e reificadas em instituições. Deste modo, estas feministas também não permitem um debate totalmente pacífico 
com as islâmicas já que também não assentem a experiência das mulheres religiosas com o transcendental como um fato legítimo na formação de suas identidades.

Alguns contrapontos a estas abordagens podem ser apresentados. Em sua obra, Mack (2003) examina a tentativa de mulheres Quakers do século XVIII de contestar normas sociais vigentes, mas a partir de um ato de obediência a Deus e não como reflexo de uma posição de vontade. Mahmood (2004), da mesma forma pesquisa como mulheres muçulmanas no Cairo desafiaram normas sociais como um ato de obediência a um poder transcendental, Deus, e não a homens ou sistemas patriarcais. Destarte, ambas as autoras, em seus estudos, tentaram fornecer uma alternativa para compreender as experiências de mulheres fora dos parâmetros de agência e emancipação, os quais sempre retomam à tradição liberal que vê a mulher como lutando, resistindo ou subvertendo e nunca como ativas (SALEM, 2013).

Ao defender que algumas escolhas são feministas e emancipatórias e outras são subservientes e opressivas, grande parte da literatura de gênero ajuda a reforçar a asserção de que mulheres religiosas necessariamente estejam sofrendo de falsa consciência e estão, portanto, distante do estágio de libertação ao qual outras mulheres já atingiram. Reside aí a criação de binários como secular/espiritual, razão/obscurantismo, ciência/religião, liberdade/opressão.

É preciso questionar como mesmo as abordagens de gênero não positivistas, que celebram a diversidade e a interdisciplinaridade em RI, por exemplo, são omissas sobre o feminismo islâmico. Essa omissão constitui um local de exclusão e violência com relação às narrativas e experiências de mulheres cuja religião é parte importante de suas identidades.

Esta lacuna pode ser explicada pelo que Mack (2003) denominou metanarrativa do secularismo que, conforme demonstra Salem (2013), informa a produção de conhecimento, incluindo os estudos de gênero nas ciências sociais, em geral, e, particularmente, nas Rl. Calcadas na metanarrativa secular, estas abordagens continuam referenciando os conceitos de autonomia e agência à luz das categorias do lluminismo e da ciência social moderna, reificando, com isto, as experiências de certas mulheres como emancipatórias e as de outras como patriarcais e opressoras. A metanarrativa secular deve ser compreendida dentro do projeto de modernidade ocidental, já que é este que reifica o papel da ciência como a única forma de 
enunciação legítima que se constitui necessariamente em oposição à religião e, logo, ao seu conhecimento considerado como fruto do obscurantismo, logo, ilegítimo.

Conforme bem argumenta Shilliam (2011), mesmo os autores pautados no pós-estruturalismo como Judith Butler, Jacques Derrida, Michel Foucault e Gayatri Chakravorty Spivak, estariam apenas contribuindo para a perpetuação da metanarrativa secular dentro do discurso acadêmico na medida em que a própria noção de "racionalidade" não é questionada. Vale ressaltar ainda que a produção de conhecimento está localizada predominantemente no Ocidente e, aqueles que se encontram às margens, como explicita Chandra Talpade Mohanty (1984) em seu texto Under Western Eyes: Feminist Scholarship and Colonial Discourses, tornam-se apenas objetos de estudo, tendo seus discursos silenciados a partir da deslegitimação do que é não-Ocidental. A partir desse contexto, as feministas islâmicas reivindicam a legitimidade em poder falar sobre si mesmas e, com isso, a possibilidade de defender seus próprios objetivos, sem que haja uma imposição da metanarrativa secular sobre seus interesses particulares.

Algumas interlocutoras do movimento feminista islâmico reivindicam o abando da epistemologia secular, conforme demonstra Salem (2013). Este movimento tem sido um campo que pode ser definido, em linhas gerais, como uma tentativa de exercer poder sobre a produção de conhecimento e os significados produzidos dentro do Islã. Acadêmicas têm tentado desconstruir interpretações misóginas do Islã por meio de metodologias islâmicas tradicionais.

A despeito disso, o feminismo islâmico enfrenta profundas críticas acerca de sua legitimidade por parte das outras vertentes feministas, pois há a crença, conforme aponta Ahmad (2015), de que os termos são contraditórios, visto que a religião, a partir de uma interpretação secular e ocidental, seria inerentemente opressora. Por isso, a autora aponta para a crítica existente sobre a impossibilidade na junção dos termos feminismo e islamismo já que seria uma contradição teórico-conceitual. Porém, Ahmad (2015, p.4) afirma que tal inflexão é errônea na medida em que é possível falar em feminismo mesmo quando inserido no campo da religião, dado que "the problems faced by women are generally the result of misguided male interpretations of the principles of Islam, as opposed to the actual religious edicts" (AHMAD, 2015, p.4). Em face disso, Salem (2013) infere que da mesma forma que a singularização e homogeneização da mulher como objeto de estudo são problemáticos, a 
caracterização das mulheres religiosas como automaticamente oprimidas também é uma forma simplista de análise.

Do mesmo modo, Moghadam (2002, p.1164) questiona: "Is it an oxymoron, a contradiction in terms? Or is it part of the already diversified and colorful spectrum of the transnational women's movement and a contributor to a "global feminism"?". Conforme a autora, esse tipo de questionamento abre caminho para que se busque uma resolução acerca do debate do feminismo islâmico, pois no âmbito dessa abordagem defende-se uma concepção bottom-up ou materialista da identidade feminista e isso, por sua vez, implica dizer que o feminismo depende mais da práxis das mulheres do que propriamente da sua ideologia. Para Rupp e Taylor (1999), a concentração na ideologia, per si, ignora o fato de que as feministas se configuram como atores em movimento social que estão, por isso, situadas em um contexto organizacional e de movimento.

Por fim, outra questão colocada por Moghadam (2002) é que dado que a política feminista é moldada por contextos históricos, culturais, políticos e sociais específicos e estes, por sua vez, estão sempre em movimento e não são fixos ou imutáveis, o conceito de feminismo, de uma maneira geral, também está em constante transformação e mudança, abrindo precedentes para que o mesmo seja contestado. Por isso, tomar uma noção de feminismo como única ou como uma verdade absoluta, limita a compreensão dos diferentes movimentos feminista e marginaliza as diferentes reivindicações e vozes das mulheres que não estão inseridas no secularismo.

\section{Considerações Finais}

O estudo em tela não teve a intenção de apresentar uma resposta à problemática levantada, por motivos óbvios. O escopo do trabalho foi iluminar a existência da grande lacuna entre os feminismos em geral e o feminismo islâmico com vistas a localizá-la no debate epistemológico secularismo versus pós-secularismo. E, na esteira destes objetivos, buscou-se advogar pela inserção deste debate nas problemáticas teóricas das $\mathrm{RI}$.

Argumentou-se que é necessário compreender o que está sendo reivindicado pelas mulheres muçulmanas à luz de um local histórico, cultural, político e social específico. Atentando-se, por isso, à noção de que as lutas feministas ocorrem dentro 
de uma comunidade de movimento social e que, à medida que passam a evoluir, englobam outros fatores e problemáticas que permeiam a discussão de gênero e, que, portanto, merecem ser tomados como categoria de análise importante. Por isso, Moghadam (2002) afirma que é possível identificar o feminismo islâmico como um feminismo entre muitos, principalmente pelo fato de que na atualidade, ele emerge como um movimento global de mulheres com uma filosofia que não está calcada nos chamados "clássicos movimentos feministas". Para além disso, ele reflete as realidades sociais e preocupações das mulheres não somente em países muçulmanos, mas crescentemente nos Estados Unidos e em países na Europa onde a diáspora muçulmana vem se ampliando.

Neste sentido, Rosi Braidotti (2008), propõe uma virada pós-secular ("the postsecular turn"), que significa o reconhecimento da presença e da importância da religião para a análise do feminismo. Conforme a autora, é necessário que se compreenda o feminismo como uma perspectiva teórica, bem como prática, que objetiva criticar as desigualdades sociais e de gênero, para promover o empoderamento das mulheres e buscar a transformação da formulação do conhecimento (MOGHADAM, 2002).

Por isso, "the postsecular turn" não se trata de uma negação ao secularismo, e, tampouco, de uma negação dos preceitos religiosos. Mas, em contrapartida, constitui a busca pelo estabelecimento de um diálogo entre as mais variadas vertentes do movimento feminista de modo que as vozes silenciadas e as reivindicações particulares sejam ouvidas e legitimadas. Na busca pela superação das dicotomias secular/religioso, liberdade/opressão, moderno/obscuro, as feministas islâmicas propõem que as mulheres, e não a religião, se encontrem no centro da teoria e da prática feminista, pois haverá, em todo o mundo, estratégias distintas para exercer o feminismo que serão postuladas por diferentes mulheres. Por esta razão, como expõem Moghissi (1993) e Shahidian (1994) insistir em uma definição estreita de feminismo é não entender ou reduzir a complexidade das relações sociais. 


\section{Referências Bibliográficas}

AHMAD, Ambar. Islamic Feminism - A Contradiction in Terms? Friedrich Ebert Stiftung, New Dheli: Fes India Paper, 2015.

AHMED, Leila. Women and gender in Islam: historical roots of a modern debate. London: Yale University Press, 1992.

BADRAN, Margot. Islamic feminism: what's in a name?. Egypt: Al-Ahram Weekly, v. 27, n. 569, p. 17-23, 2002.

. Between secular and islamic feminism/s: reflections on the Middle East and Beyond. Journal of Middle East Women's Studies, v. 1, n. 1, p. 6-28, 2005.

Re-defining Feminism/s, Re-imagining Faith? Margot Badran on Islamic Feminism. Al-Raida, v. 22, n. 3, p. 57-88, 2005.

2009 .

Feminism in Islam: secular and religious convergences. London: Oxford Press,

Feminismo islámico en marcha. CLEPSYDRA, v. 18, n. 9, p. 69-84, 2010.

BALDI, César. Feminismo islâmico: notas para um debate. Revista do Núcleo de Estudos e Pesquisas em gênero e direito, v.1, n. 2, p. 1-89, 2010.

BELLOTTI, Karina Kosicki. Gênero e Religião. Revista Aulas, v. 27, n. 4, p. 1-7, 2007.

BRAIDOTTI, Rosi. In Spite of the Times: The postsecular turn in Feminism. Theory, Culture \& Society, v. 25, n. 6. p. 1-24, 2008.

CAMPBELL, David. Poststructuralism. In: DUNNE, Tim; KURKI, Milja; SMITH, Steve (eds). International Relations Theories: discipline and diversity. 2nd edition, New York: Oxford University Press, 2010. p. 203-228.

CHIN, Christine. Service and Servitude: Foreign Female Domestic Workers and the Malaysian 'Modernity' Project. New York: Columbia University Press, 1998.

CHOWDHRY, G. NAIR, S. Power in a postcolonial world: race, gender, and class in international relations. In: CHOWDHRY, G. NAIR, S (eds.). Power, Postcolonialism and International Relations: Reading Race, Gender, and Class. London: Routledge, 2002, p. 10-32.

ENLOE, Cynthia. Margins, silences and bottom rungs: how to overcome the underestimation of power in the study of international relations. In: SMITH, S.; BOOTH, K.; ZALEWSKI, M. (eds.) International Theory: positivism \& beyond. New York: Cambridge University Press, 1996, p. 186-202. 
FRANCO, Clarissa de. Feminismo Islâmico face ao Feminismo Secular: uma nova consciência de gênero de um oriente que rejeita a ocidentalização. Último Andar, v. 27, n. 2, p. 84-92, 2016.

HALLIDAY, Fred. Hidden from International Relations: Women and the International Arena. Millennium: Journal of International Studies, v. 17, n, 3, p. 419-428.

HOOPER, C. Manly States: Masculinities, International Relations, and Gender Politics. New York: Columbia University Press, 2001.

KARAM, Azza. Women, Islamism and the state: contemporary feminisms in the Middle East. London: Macmillan, 1998.

KEMNITZ, Eva-Maria von. O Orientalismo na perspectiva de Edward Said. Colóquio sobre a Vida, Pensamento e Obra de Edward Said. 2009. Disponível em: <http://webcache.googleusercontent.com/search?q=cache:Y29hRa0QmnoJ:www.mp pm-palestina.org/index.php/component/docman/doc_download/25-

\%3Fltemld\%3D5+\&cd=1\&hl=pt-BR\&ct=clnk\&gl=br>. Acessado em 13 de abril de 2017.

KIMMEL, M. S. The Gendered Society. Oxford: Oxford University Press, 2004.

KEOHANE, R. O. Beyond Dichotomy: Conversations between International Relations and Feminist Theory. International Studies Quarterly, v. 42, n. 1, p. 193-197, 1998.

. International Institutions: Two Approaches. International Studies Quarterly, v. 32, n. 4, p. 379-396, 1988.

KURKI, M.; WIGHT, C. International Relations and Social Science. In: DUNNE, Tim; KURKI, Milja; SMITH, S. (org.). International Relations Theories: discipline and diversity. $2^{\text {nd }}$ edition. New York: Oxford University Press, 2010. p. 13-33.

LAPID, Y. The Third Debate: On the Prospects of International Theory in a PostPositivist Era. International Studies Quarterly, v. 33, n. 3, p. 235-254, 1989.

LIMA, Cila. Um Recente Movimento Político-Religioso: feminismo islâmico. Estudos Feministas, v. 22, n 2, p. 675-686, 2014.

LOCKER, Birgit; PRÜGL, Elisabeth. Feminism and Constructivism: Worlds Apart or Sharing the Middle Ground? International Studies Quarterly, v. 45, n. 1, p. 111-129, 2001.

MACK, Phyllis. Religion, feminism and the problem of agency: reflections on Eighteenth-Century Quakerism. Signs, v. 29, n.1, p. 149-177, 2003.

MAHMOOD, Saba.Women's Agency within Feminist Historiography. The Journal of Religion, v. 84, n. 4, p. 573-579, 2004. 
MARQUES, Vera Lúcia Maia. Mulheres e Mulçumanas. 2010. Disponível em: < http://www.fazendogenero.ufsc.br/9/resources/anais/1278288843 ARQUIVO Mulher eseMuculmanas\%5B2\%5D.pdf>. Acessado em 06 de Agosto de 2017.

MOGHADAM, Valentine M. Islamic Feminism and Its Discontents: Toward a Resolution of the Debate. Signs, v. 27, n. 4, p. 1135-1171, 2002.

MOGHISSI, Haideh. Women in the Resistance Movement in Iran. In: AFSHAR, Haleh (eds.). Women in the Middle East: Perceptions, Realities, and Struggles for Liberation. New York: St. Martin's, 1993, p. 158-171.

MOHANTY, Chandra Talpade. Under Western Eyes: Feminist Scholarship and Colonial Discourses. Boundary 2, v. 12, n. 3, p. 333-358, 1984.

PADRO, Abdenuur. La emergencia del feminismo islámico. In: La emergencia del feminismo islámico. Selección de ponencias del Primer y Segundo Congreso Internacional de Feminismo Islámico. Asbab, v. 2, n. 2, p. 3-27, 2008

PETERSON, V. S.; RUNYAN, A. S. Global Gender Issues. 2nd edn. Boulder, CO: Westview, 1999.

RUBY, Jennie. Is this a Feminist war?. In: HAWTHORNE, Susan. WINTER, Bronwyn (eds.). Feminist Perspectives. Spirifex: Melbourne, 2002. p. 148-15.

RIDZUAN, Nadiah Bte. Women, Islam and Feminism in Postcolonial Malaysia and Singapore. Tese de mestrado em Ciência Política, National University of Singapore, 2011.

RUPP, Leila J. TAYLOR, Verta. Forging Feminist Identity in an Inter-national Movement: A Collective Identity Approach to Twentieth-Century Feminism. Signs: Journal of Women in Culture and Society, v. 24, n. 21, p. 363-86, 1999.

SAID, Edward W. Orientalismo: O Oriente como invenção do Ocidente. São Paulo: Companhia das Letras, 1990.

SALEM, Sara. Feminist critique and Islamic feminism: the question of intersectionality. Academic Journal, v. 1, n. 1, 2013. p. 172-182, 2013.

SHAHIDIAN, Hammed. The Iranian Left and 'The Woman Question' in the Revolution of 1978-79. International Journal of Middle East Studies, v. 26, n. 2, p. 223-47, 1994.

SHILLIAM, Robbie. The perilous but unavoidable terrain of the non-West. In: SHILLIAM, Robbie (eds.). International relations non-Western Thought: imperialism, colonialism and investigations of global modernity. New York: Routledge, 2011. p. 1226.

SILVA, Eliane Moura da. Religião, Diversidade e Valores Culturais: conceitos teóricos e a educação para a Cidadania. Revista de Estudos da Religião, v. 23, n. 2, p. 1-14, 2004 
SMITH, S. Positivism and Beyond. In: SMITH, S.; BOOTH, K.; ZALEWSKI, M. (eds.). International Theory: positivism \& beyond. New York: Cambridge University Press, 1996, p. 11-46.

.The Discipline of international relations: still an American social sciences?

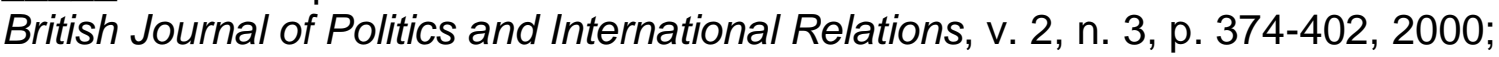

. The United States and the Discipline of International Relations: "Hegemonic Country, Hegemonic Discipline”. International Studies Review, v. 4, n. 2, p. 67-85, 2002.

Introduction: Diversity and Disciplinarity in International Relations Theory. In: DUNNE, Tim, et. al (eds.). International Relations Theory: discipline and diversity. New York: Oxford University Press, 2010. p. 1-13.

SPIVAK, Gayatri Chakravorty. Pode o Subalterno Falar? Belo Horizonte: Editora UFMG, 2010.

STEANS, J. Gender in International Relations: an introduction. New Brunswick: Rutgers University Press, 1998.

STERLING-FOLKER, J. (ed.). Making sense of International Relations Theory. Boulder, CO: Lynne Rienner, 2006.

SYLVESTER, Christine. The Contributions of Feminist Theory to International Relations. In: SMITH, S,; BOOTH, K,; ZALEWSKI, M. (Eds.). International Theory: positivism and beyond. Cambridge University Press, 1996, p. 254-278.

TICKNER, J. A. You Just Don't Understand: Troubled Engagements between Feminists and IR Theorists. International Studies Quarterly, v. 41, n. 4, p. 611-632, 1997.

. Gendering World Politics. New York: Columbia University Press, 2001.

Gender in World Politics, In: BAYLIS, John et al. (Orgs.) $5^{\text {th }}$ Ed., The Globalization of World Politics. Oxford: Oxford University Press, 2011. p. 262-277.

TICKNER, J. A.; SJOBERG, L. Feminism. In: DUNNE, Tim; KURKI, Milja; SMITH, Steve (eds). International Relations Theories: discipline and diversity. $2^{\text {nd }}$ edition. New York: Oxford University Press, 2013, p. 185.202.

TRUE, J. Feminism. In: BURCHILL, S. at al (eds.). Theories of International Relations. 3rd ed. New York: Palgrave Macmillan, 2005, p. 213-234.

. The Ethics of Feminism. In: REUS-SMIT, Christian; SNIDAL, Duncan (eds.). The Oxford Handbook of International Relations. New York: Oxford University Press, New York, 2010, p. 408-424. 
WATSON, Alison. Gender and Other 'Others'. In: SALMON, T. C. IMBER, M. F. Issues in International Relations. 2nd ed., London: Routledge, 2008, p. 195-206.

WEBER, C. Gender: Is gender a variable? In: WEBER, C (org.). International Relations Theory: a critical introduction. 3rd Ed., London: Routledge, 2010.

WEAVER, O. The rise and fall of the inter-paradigm debate. In: SMITH, S.; BOOTH, K.; ZALEWSKI, M. (eds.) International Theory: positivism \& beyond. New York: Cambridge University Press, 1996, p. 149-187.

WHITWORTH, S. Feminism and International Relations: Towards a political Economy of Gender in Interstate and Non-Governmental Institutions. New York: Palgrave Macmillan Press, 1997.

ZALEWSKI, M.; ENLOE, C. Feminist Theory and International Relations. In: BOWKER, M.; BROWN, R. (eds.). From Cold War to Collapse: Theory and World Politics in the 1980's. Pennsylvania: The Pennsylvania State University Press, 1993, p. 115-144.

Recebido em 24 de abril de 2017. Aprovado em 29 de julho de 2017. 